Review Article

\title{
Anabolic-Androgenic Steroid Misuse: Mechanisms, Patterns of Misuse, User Typology, and Adverse Effects
}

\author{
Jack B. Ding, ${ }^{1}$ Marcus Z. Ng, ${ }^{1}$ Steven S. Huang, ${ }^{1}$ Mark Ding, ${ }^{1}$ and Kevin Hu ${ }^{2}{ }^{2}$ \\ ${ }^{1}$ University of Adelaide, Adelaide 5005, Australia \\ ${ }^{2}$ Division of Medicine, Lyell Mcewin Hospital, Adelaide 5112, Australia \\ Correspondence should be addressed to Kevin Hu; kevin.hu@sa.gov.au
}

Received 25 September 2021; Accepted 16 November 2021; Published 10 December 2021

Academic Editor: Nancy J. Rehrer

Copyright (c) 2021 Jack B. Ding et al. This is an open access article distributed under the Creative Commons Attribution License, which permits unrestricted use, distribution, and reproduction in any medium, provided the original work is properly cited.

Anabolic-androgenic steroids (AAS) encompass a broad group of natural and synthetic androgens. AAS misuse is highly prevalent on a global scale, with the lifetime prevalence of AAS misuse in males being estimated to be around $6 \%$, with 15 to $25 \%$ of male gym attendees using it at any one time. AAS are associated with sudden cardiac death, neuropsychiatric manifestations, and infertility. The average AAS user is unlikely to voluntarily declare their usage to a physician, with around 1 in 10 actively engaging in unsafe injection techniques. The aim of this paper is to review the current evidence base on AAS with emphasis on mechanisms of action, adverse effects, and user profiles that are most likely to engage in AAS misuse. This paper also reviews terminologies and uses methods specific to the AAS user community.

\section{Background and Introduction}

Anabolic-androgenic steroids (AAS) are more commonly referred to as anabolic steroids and encompass a diverse group of both synthetic and endogenous androgens [1]. Testosterone, an endogenous androgen, was isolated and characterized in 1935 and subsequently made available for synthesis and exogenous administration [2]. Since then, substantial research and development have led to the creation of numerous testosterone derivatives with structural alterations that result in properties unique to each derivative. The earliest use of AAS was in the context of competitive sport, including its high profile utilization by the 1954 Russian weight lifting team at the Olympics [3]. With the subsequent creation of international antidoping agencies such as the World Anti-Doping Agency and explicit banning of AAS use by the International Olympics Committee in 1967, its use among elite athletes has attenuated. Instead, the use of AAS has become more pervasive among users at a nonelite level, with a 2014 meta-analysis of 187 studies estimating the lifetime prevalence of AAS use in men to be around 6\% and a 2005 paper suggesting its prevalence amongst male gym attendees to be around $25 \%[4,5]$.
However, the average clinician may not encounter a significant number of clinical presentations related to AAS use for several reasons. First, the most devastating adverse effects of AAS such as an increased risk of premature death from all causes or twice-fold increased cardiovascular mortality rate manifest suddenly and definitively [6]. Second, AAS consumers are rarely proactive with disclosing their use status with their physicians, with one study finding that $56 \%$ of AAS users had never informed any physician that they use or have used AAS [7]. Alarmingly, this is despite 1 in 10 reporting unsafe injection techniques and close to $100 \%$ reporting subjective side effects [5]. The primary reason behind this underreporting has been suggested by some to be due to a universal sense of distrust among AAS users regarding the knowledge the average physician has on AAS [8]. Further, physicians rarely specifically inquire about AAS use during history taking, thereby missing an opportunity to establish rapport about the topic [7]. Indeed, anecdotal reports of advice given by clinicians inaccurately purporting that AAS are ineffective for muscle growth have surfaced, with some commentors arguing that such blanket statements can prematurely sever any chance of developing rapport and generating critical discussion with AAS users [8]. Instead, 
commentors have suggested that an in-depth understanding of AAS science and mechanisms is necessary for the establishment of foundational discussion with AAS users, which can provide a physician with a footing to later effectively pivot to conversations regarding AAS discontinuation [8]. While there is an abundance of literature pertaining to the side effects of AAS use, there is a paucity of reviews that discuss the motives, efficacy, and patterns of AAS misuse. This review aims to fill this gap while also refreshing and updating the physician about the underlying basic science of AAS and the prognostic implications of AAS use.

\section{A Review of Testosterone}

The primary function of the testes is to produce testosterone and maintain an environment optimized for spermatogenesis [9]. These dual functions are coordinated by the overarching hypothalamic pituitary gonadal (HPG) axis. The first step of the axis involves the pulsatile release of gonadotropin releasing hormone $(\mathrm{GnRH})$ from the hypothalamus, which reaches the anterior pituitary through the hypophyseal-portal system [10]. The anterior pituitary is stimulated by $\mathrm{GnRH}$ and in result secretes follicle-stimulating hormone (FSH) and luteinizing hormone ( $\mathrm{LH})$ into the systemic circulation. FSH acts on Sertoli cells in the seminiferous tubules, where it promotes spermatogenesis. $\mathrm{LH}$ targets Leydig cells located adjacent to the seminiferous tubules, where testosterone production is stimulated [11]. Notably, the intratesticular testosterone concentration is typically 50-100 times higher than the serum concentration of testosterone [12]. Intratesticular testosterone helps optimize spermatogenesis, and the steep concentration gradient helps maintain systemic testosterone levels, where it exerts additional effects on androgen sensitive tissues.

The classic effects of serum testosterone derive from its interaction with the androgen receptor. Testosterone binding to the intracytosolic receptor leads to its transport to the nucleus, where it directly regulates gene transcription and protein synthesis [13]. An androgen is defined as any natural or synthetic steroid that binds to the androgen receptor that results in the stimulation of postreceptor functions [14]. The action of testosterone does not chiefly revolve around the androgen receptor modulation. Under physiologic circumstances, there is a constant stream of prereceptor, receptor, and postreceptor mechanisms [13]. The primary prereceptor modulations of serum testosterone involve a portion of it being converted into $17 \beta$-estradiol by aromatase and another portion into dihydrotestosterone (DHT) by $5 \alpha$-reductase [15]. Since adipose tissue contains a significant amount of aromatase, obesity can result in increased levels of $17 \beta$-estradiol due to increased conversion of testosterone by aromatase [16]. Nandrolone (19-nortestosterone) is an endogenously produced steroid that exists as an intermediate in the process by which aromatase converts testosterone to estradiol. 19-Nortestosterone derivatives are one of the main classes of AAS. Under physiologic circumstances, 19-nortestosterone levels are not present in the bloodstream in appreciable quantities [17]. Nandrolone differs from other AAS in that it is also a potent progestogen that exhibits relatively lesser androgenic effects in tissues such as the prostate and scalp [18]. It is an agonist of both the androgen receptor and the progesterone receptor. Its progestogenic properties result in substantial antigonadotropic activity, resulting in additional suppression of the HPT axis [19]. DHT is a more potent androgen than testosterone, exhibiting over $3 \mathrm{x}$ higher affinity for the androgen receptor. The physiologic functions of DHT differ from testosterone in that it primarily signals through intracine and paracrine mechanisms in tissues where 5-alpha reductase is concentrated, exhibiting targeted local effects in contrast to the broader overarching effects of testosterone [20]. An example of this is the prostate, where its levels are up to 10-fold higher than serum testosterone, due to high local concentrations of 5-alpha reductase [21]. Unlike testosterone, DHT derivatives such as androstanolone cannot be targeted by aromatase, and therefore administration of high doses of exogenous DHT poses minimal risk for estrogenic side effects [22]. Despite DHT being described as a potent androgen receptor agonist, it has very weak anabolic effects. This is likely because 3a-hydroxysteroid dehydrogenase, an enzyme concentrated in skeletal muscle, has high affinity for DHT derivatives and converts it into metabolites that have very weak affinity for the androgen receptor [23]. Due to all this, the role DHT plays as a circulating androgen is likely minor compared to testosterone. Indeed, the serum concentrations of DHT do not necessarily correlate with its intracellular concentrations [15].

Under normal physiologic circumstances, androgen receptors are saturated by endogenous testosterone, even if the levels are at the lower range of normal for males. This detail contributed to decades of debate as to whether supraphysiologic doses of testosterone stimulate additional anabolic effects on muscle size and strength [24]. The current consensus is that androgenic anabolic steroids do indeed improve both. One study randomized 61 eugonadal men into five groups, with each receiving various doses of exogenous testosterone for 20 weeks. By the end of the trial, the men who received $600 \mathrm{mg}$ injections gained on average $7.9 \mathrm{~kg}$ of lean muscle mass and lost about $1 \mathrm{~kg}$ of body fat. Remarkably, participants were specifically instructed not to engage in any strength training or moderate or heavy aerobic exercise routines during the period of study, with this request being reiterated every 4 weeks [25]. Since androgen receptors are normally saturated by physiologic levels of testosterone, yet supraphysiologic doses of testosterone can increase muscle mass and body strength, the anabolic effects of exogenous testosterone may be explained by mechanisms other than androgen receptor modulation [26]. One possibility involves modulation of the glucocorticoid receptor. Animal studies have shown that exogenous testosterone is effective at preventing atrophy secondary to glucocorticoid use [27]. Human studies have shown that AAS can displace glucocorticoids bound to glucocorticoid receptors [28]. Since glucocorticoids exert profound antagonistic effects on skeletal muscle anabolism, suppression of its action at the receptor level may result in an overall increase in muscle mass [29]. Inhibition of glucocorticoid activity likely results 
in activation of the growth-hormone (GH) and insulin-like growth factor (IGF-1) axis, where it usually has a suppressive effect. Both IGF-1 and GH are considered 'anabolic giants' in the context of skeletal muscle growth and repair, and thus an intensification of their effects could potentially explain some of the massive skeletal muscle gains seen with AAS use [30]. Other studies have shown that AAS administration can result in androgen receptor downregulation. Since androgens can also competitively bind to estrogen receptors, if the androgen receptors are downregulated, they can interact with estrogen receptors and through that exert an antiestrogenic effect [26]. To clarify, this is not to say that AAS administration lowers estrogen levels. Rather, one study found that, over 26 weeks of exogenous anabolic steroid administration, their male participants demonstrated a 2.3fold increase in serum testosterone concentration. Conversely, the estradiol levels of the subjects rose by around 7fold, to approximately the normal range for females, with a reciprocal decrease in FSH and LH levels. $80 \%$ of their participants developed gynecomastia, likely as a result of the estradiol increase [31]. The significantly elevated estradiol levels can be explained by the normal activity of aromatase, which converts androstenedione to estrone and testosterone to estradiol [32]. At supraphysiologic testosterone levels, a greater amount of estradiol would be produced through this mechanism.

The satellite effects testosterone and other AAS have on other hormones such as estradiol or progesterone differ depending on the type of AAS. The variation is due to differences in chemical properties and ultimately leads to different adverse effect profiles between each type. The structural modifications synthetic AAS have on endogenous testosterone were likely designed with specific intentions in mind, such as maximizing anabolic effects while simultaneously minimizing androgenic properties [33]. Examples of structural modifications to the basic testosterone structure include the addition of a benzyl, hydroxyl, methyl, or ethyl at one or more sites [34]. 'Designer steroids' refers specifically to anabolic steroids that are considered to have been designed and synthesized with the explicit intention of evading doping tests in competitive sport [35]. While records of designer steroids are elusive by nature, one example of their existence is epitestosterone propionate, which was manufactured as part of the former German Democratic Republic's (GDR) state funded doping program [36].

2.1. Typology of the AAS User. As with any illicit substance user base, the AAS community is very diverse in terms of motivations and use patterns and can be difficult to categorize. Still, attempts have been made to identify typical typologies of users, as the findings may be important for shaping public health policy. Notably, qualitative stratification is not specific to AAS; studies have been applied to the opioid and alcohol misuse populations for instance [37, 38]. Christiansen and colleagues proposed a classification method in 2016, based on a review of international literature and each authors' research experience with AAS misusers
[39]. They proposed four classifications: (1) the Expert type; (2) the YOLO type; (3) the Athlete type; and (4) the Wellbeing type. In their synthesis of these typologies, they focused on a two-dimensional perspective of AAS use, which is effectiveness and perceived risk.

Christiansen and colleagues described "the Expert type" as taking a scholarly approach to AAS, their use patterns are measured, and the risks they take are generally measured. The "YOLO type" (You Only Live Once) is in some ways the archetypal opposite in that their actions are frequently spontaneous and are often motivated by rapid progress. The "Athlete type" is primarily engaged in competitive sports and is motivated by succeeding in their niche, and finally the "Wellbeing type" centralizes on physical aesthetics and tends to exhibit lower risk use strategies [39].

Zahnow and colleagues furthered these proposed typologies in 2018 by using cluster analysis followed by multinomial logistic regression on survey data from a sample of 611 AAS users across Wales, England, and Scotland [40]. They discovered four distinct categories within their data, each seeming to correspond to four typologies proposed by Christiansen. Specifically, $11 \%$ of respondents seemed to correspond to the "YOLO type," 38\% to the "Wellbeing type," 25\% to the "Athlete type," and 25\% to the "Expert type." To our knowledge, this study is the first and latest attempt at quantifying a typographic analysis of AAS users. Importantly, it has substantiated the notion of distinct subclasses within the AAS user base and that AAS users are diverse in motives and use patterns. Overall, however, our current typographic understanding of AAS users is in a relative infancy, especially since that the population analyzed is limited to the United Kingdom and that other typologies may exist and are yet to be discovered and conceptualized.

2.2. Classes of AAS Compounds. Broadly, AAS compounds may be classified into three main groups, testosterone esters, 19-nortestosterone derivatives, and dihydrotestosterone derivatives, and may be further stratified based on route of consumption (oral versus intramuscular) [41, 42]. Table 1 provides an overview of these three classes and some of their common trade names.

2.3. Basic AAS Use Methods and Nomenclature. Most AAS regimens include one or more compounds from Table 1 taken at a supraphysiologic dose. Physiologic levels of serum testosterone in adult males range from 300 to $1,000 \mathrm{ng} / \mathrm{dL}$, with up to $11.0 \mathrm{mg}$ testosterone produced per day, whereas normal serum DHT ranges from 50 to $74 \mathrm{ng} / \mathrm{dL}[15,43]$. For perspective, one study found that over half of AAS users were administered weekly doses of androgens exceeding $1000 \mathrm{mg}$ [5].

A review by Graham et al. identified several key nonscientific AAS use methods and terms to describe them among various sources in the bodybuilding community [44]. These terms and their interpretation are tabulated in Table 2. 
TABLE 1: An overview of selected injectable and oral anabolic steroids.

\begin{tabular}{|c|c|c|}
\hline \multicolumn{3}{|c|}{ Injectable AAS } \\
\hline $\begin{array}{l}\text { Dihydrotestosterone } \\
\text { derivatives }\end{array}$ & Testosterone derivatives & 19-nortestosterone derivatives \\
\hline Drostanolone (Masteron) & Testosterone cypionate (Test C, Testex Leo) & $\begin{array}{c}\text { Nandrolone compounds (Deca Durabolin, NPPP, Pondus, } \\
\text { Testobolin) }\end{array}$ \\
\hline \multirow{3}{*}{$\begin{array}{l}\text { Mesterolone (Proviron) } \\
\text { Stanozolol (Stromba, } \\
\text { Winstrol) }\end{array}$} & Testosterone enanthate (Test E, Testoviron) & Trenbolone compounds (“Tren”) \\
\hline & Testosterone propionate (Test Prop) & \\
\hline & $\begin{array}{l}\text { Testosterone decanoate } \\
\text { Boldenone undecylenate (Equipoise) } \\
\text { Sustanon } 250\end{array}$ & \\
\hline \multicolumn{3}{|c|}{ Oral anabolic steroids } \\
\hline $\begin{array}{l}\text { Dihydrotestosterone } \\
\text { derivatives }\end{array}$ & Testosterone derivatives & Prohormones \\
\hline Oxandrolone (Anavar) & Methyltestosterone & Methasterone (superdrol) \\
\hline Oxymetholone (Anadrol) & Metandienone ("Dianabol”) & 1-Androstenedione (andro) \\
\hline Metenolone (Primobolan) & Fluoxymesterone (Halotestin) & Dehydroepiandrosterone (DHEA) \\
\hline Stanozolol (Winstrol) & $\begin{array}{l}\text { Chlorodehydromethyltestosterone } \\
\text { (Turinabol) }\end{array}$ & \\
\hline
\end{tabular}

TABLE 2: Common terminologies used by the AAS user community.

\begin{tabular}{|c|c|}
\hline Terminology & Interpretation \\
\hline $\begin{array}{l}\text { Stacking/blending/ } \\
\text { shotgunning } \\
\text { Tapering }\end{array}$ & $\begin{array}{c}\text { Combining more than one AAS or non-AAS drug into a single regimen to be taken concurrently. This could } \\
\text { involve mixing oral and injectable types or taking compounds intended for veterinary use. } \\
\text { Gradually weaning an AAS dose down. }\end{array}$ \\
\hline Plateauing & $\begin{array}{r}\text { When a drug becomes ineffective at its cu } \\
\text { the }\end{array}$ \\
\hline Cycle & $\begin{array}{r}\text { Using one or more AAS for a fixed period, ranging anywhere } \\
\text { approximately a similar duratio }\end{array}$ \\
\hline Pyrar & $\begin{array}{c}\text { Gradually maximizing the dosage of an AAS and then gradually minimizing the dosage of the same drug to } \\
\text { zero over a predefined amount of time. }\end{array}$ \\
\hline $\begin{array}{l}\text { Blast a } \\
{[45]}\end{array}$ & $\begin{array}{l}\text { Alternating between periods of high and low doses of AAS, but never completely ceasing drug use. Periods of } \\
\text { high AAS dose are a 'blast' phase, whereas periods of lower AAS dose are a 'cruise' phase. }\end{array}$ \\
\hline
\end{tabular}

\section{Performance-Enhancing Drugs (PEDs) in the Context of AAS Use}

AAS regimens frequently include one or more ancillary drugs to augment the efficacy of the primary AAS or to offset any undesirable side effects [45]. Performance-enhancing drugs (PEDs) in the context of AAS use characterize multiple classes of supplementary compounds that have distinct hormonal interactions. Table 3 provides an overview of popular PEDs and their intended effects and side effects.

\subsection{Performance-Enhancing Drugs in the Postcycle Period.} The term 'postcycle' describes the time immediately following an AAS cycle when users typically encounter a myriad of side effects, such as gynecomastia and hypogonadism secondary to low endogenous testosterone levels and or loss of exogenous testosterone supply following cycle completion [49]. Counteracting AAS side effects is one popular use case of PEDs in the bodybuilding community, with a 2018 survey of 231 AAS users finding that $56 \%$ of participants reported that they had engaged in some form of postcycle therapy [50].

Karavolos et al. used a systematic online search process to investigate the various websites and forum communities where participants were able to request and or deliver advice pertaining to counteracting AAS induced side effects. They found that up to a third of the identified websites claimed to sell AAS and or products intended to combat AAS side effects without a prescription. Personal anecdotes and recommendations from anonymous participants formed the bulk of advice on the discussion forums. Scientific publications were cited by participants, though they were frequently taken out of context or were ungeneralizable to the AAS user population [46].

Table 4 represents commonly encountered side effects in the "postcycle" period and strategies frequently advocated to offset them in the AAS user community.

3.2. Adverse Effects of AAS Use. The adverse effect profile of exogenous AAS administration is a source of contention, with some raising the possibility that interpretations of data had been exaggerated [56]. A 2010 review concluded that the prevalence of somatic and psychiatric adverse effects was limited and that the typical user was given AAS with the intention to augment their sporting accomplishments [57]. Conversely, others have suggested that AAS misuse is a public health issue and that the widespread presence of androgen receptors in the body is one possible explanation 
TABLE 3: Selected performance-enhancing drugs used in relation to AAS.

\begin{tabular}{|c|c|c|c|}
\hline Class & Selected formulations & Intended effects & Adverse effects \\
\hline $\begin{array}{l}\text { Aromatase inhibitors } \\
{[46]}\end{array}$ & $\begin{array}{l}\text { Anastrozole, letrozole, } \\
\text { exemestane }\end{array}$ & $\begin{array}{l}\text { Increase pituitary gonadotrophin release } \\
\text { and therefore increasing endogenous } \\
\text { testosterone release by reducing estrogenic } \\
\text { negative feedback }\end{array}$ & $\begin{array}{l}\text { Decreased bone density, sexual } \\
\text { dysfunction, central adiposity }\end{array}$ \\
\hline SERMs [46] & Clomiphene, tamoxifen & $\begin{array}{c}\text { Increase pituitary gonadotrophin release } \\
\text { and therefore increasing endogenous } \\
\text { testosterone release by reducing estrogenic } \\
\text { negative feedback }\end{array}$ & $\begin{array}{l}\text { Vasomotor symptoms, visual } \\
\text { disturbances, headaches }\end{array}$ \\
\hline $\begin{array}{l}\text { Fat-burning } \\
\text { compounds }\end{array}$ & $\begin{array}{l}\text { Dinitrophenol, liothyronine } \\
\text { (T3), clenbuterol }\end{array}$ & Achieve lower body fat percentages & Hypertension, arrhythmias \\
\hline Insulin & Lispro, glargine & Increase lean muscle mass & Hypoglycaemia \\
\hline $\begin{array}{l}\text { Human growth- } \\
\text { hormone }(\mathrm{hGH})\end{array}$ & Varied & Hypertension, elevated malignancy risk & Hypertension \\
\hline Diuretics & $\begin{array}{l}\text { Furosemide, } \\
\text { hydrochlorothiazide, } \\
\text { torsemide }\end{array}$ & $\begin{array}{l}\text { Reduce water retention to improve } \\
\text { perceived muscle aesthetics usually taken } \\
\text { before competition }\end{array}$ & $\begin{array}{c}\text { Electrolyte disturbances, especially } \\
\text { hypokalaemia }\end{array}$ \\
\hline SARMs & Andarine, Ostarine, Ligandrol & Increase lean muscle mass & Unknown (experimental compounds) \\
\hline $\begin{array}{l}\text { Human chorionic } \\
\text { gonadotropin (hCG) } \\
{[47]}\end{array}$ & Varied & $\begin{array}{l}\text { Counteract AAS suppression of testicular } \\
\text { function and volume, raise testicular } \\
\text { testosterone production }\end{array}$ & $\begin{array}{l}\text { Diabetes, cardiomyopathy, renal } \\
\text { failure, hepatotoxicity, edema, carpal } \\
\text { tunnel syndrome, joint pain, fatigue }\end{array}$ \\
\hline Site enhancement oil & $\begin{array}{l}\text { Water-based, oil-based, and } \\
\text { silicone-based injection } \\
\text { options }\end{array}$ & $\begin{array}{l}\text { Improve perceived aesthetics of muscle by } \\
\text { locally expanding volume }\end{array}$ & Infection \\
\hline Creatine [48] & Varied & $\begin{array}{l}\text { Increase performance in short-duration, } \\
\text { high-intensity exercises }\end{array}$ & $\begin{array}{l}\text { Water retention, gastrointestinal } \\
\text { symptoms, fatigue diarrhoea, liver } \\
\text { and renal complications }\end{array}$ \\
\hline
\end{tabular}

TABLE 4: Commonly encountered side effects in the "postcycle" period.

\begin{tabular}{|c|c|c|c|}
\hline Side effect & $\begin{array}{c}\text { Examples of self-initiated } \\
\text { therapies }\end{array}$ & Possible mechanisms & Important findings \\
\hline Gynecomastia [49] & $\begin{array}{l}\text { SERMS (tamoxifen) } \\
\text { AIs (anastrozole, } \\
\text { letrozole, exemestane) } \\
\text { Dopamine agonists } \\
\text { (cabergoline and } \\
\text { bromocriptine) for } \\
\text { galactorrhea }\end{array}$ & $\begin{array}{l}\text { SERMs inhibit pituitary E2 receptors, } \\
\text { and therefore stimulate pituitary } \\
\text { gonadotropin release and subsequent } \\
\text { endogenous testosterone secretion } \\
\text { Aromatase inhibitors reduce the } \\
\text { conversion of testosterone to } \\
\text { estrogens, which exert powerful } \\
\text { negative feedback on the HPT axis }\end{array}$ & $\begin{array}{l}\text { Tamoxifen may effectively treat acute } \\
\text { gynecomastia [51] } \\
\text { Chronic gynecomastia may only } \\
\text { respond to surgical treatment } \\
\text { AAS users are also known to } \\
\text { prophylactically administer SERMS and } \\
\text { AIs to avoid developing gynecomastia }\end{array}$ \\
\hline $\begin{array}{l}\text { ASIH causing testicular } \\
\text { atrophy, infertility, and low } \\
\text { endogenous testosterone } \\
\text { levels [46][ }\end{array}$ & $\begin{array}{l}\text { hCG injections (on-cycle) } \\
\text { hCG injections } \\
\text { (postcycle) } \\
\text { SERMs (clomiphene, } \\
\text { raloxifene) } \\
\text { AIs (anastrozole, } \\
\text { letrozole, exemestane) }\end{array}$ & $\begin{array}{l}\text { The human placenta normally } \\
\text { produces hCG, although synthetic } \\
\text { forms are also available for exogenous } \\
\text { administration } \\
\text { hCG and LH bind to the same LH } \\
\text { receptor [52] } \\
\text { Serum and intratesticular } \\
\text { testosterone levels can rise following } \\
\text { hCG injections [53] }\end{array}$ & $\begin{array}{l}\text { There is limited case report data } \\
\text { demonstrating efficacy in accelerating } \\
\text { return to endogenous testosterone } \\
\text { production and spermatogenesis } \\
{[54,55]}\end{array}$ \\
\hline $\begin{array}{l}\text { Sexual dysfunction (low } \\
\text { libido, erectile dysfunction) } \\
\text { [49] }\end{array}$ & $\begin{array}{l}\text { PDE-5 inhibitors } \\
\text { (sildenafil, tadalafil) } \\
\text { SSRI (dapoxetine) } \\
\text { Herbal remedies } \\
\text { Dopamine agonists } \\
\text { (cabergoline) }\end{array}$ & & $\begin{array}{c}\text { Commentators have suggested PDE-5 } \\
\text { inhibitors as the first-line treatment and } \\
\text { discouraged herbal remedies and } \\
\text { dapoxetine use [45] }\end{array}$ \\
\hline
\end{tabular}

for AAS side effects being pervasive across multiple organs and systems [26].

Among the complications of AAS use, cardiovascular side effects have been postulated to have the strongest mortality altering consequences, with some studies suggesting it to be the root cause of premature death in AAS users in up to $33-66 \%$ of cases, with the remaining being mainly caused by liver failure, cancer, and suicide [58]. A 
2019 retrospective study of 545 AAS users reported mortality rates to be around three times higher compared to matched male controls (95\% CI 1.3-7.0) [59]. In addition, the AAS cohort was found to be significantly more likely to present to be admitted to hospital compared to the control group. In a postmortem review, an analysis of 19 cases in which autopsy had excluded extracardiac mechanisms of death revealed left ventricular hypertrophy with concomitant fibrosis to be the most common finding [60]. These pathologic findings corroborate with clinical findings, such as significantly reduced left ventricular systolic and diastolic function, as reported in a 2017 cross-sectional study of 140 weightlifters [61]. While the mechanisms behind cardiac death in AAS users are incompletely understood, four possibilities have been proposed, which include (1) atherosclerosis potentiation model, (2) thrombosis model, (3) coronary vasospasm, and (4) direct cardiac injury [62]. The stimulatory effect of exogenous AAS administration on hematopoiesis theoretically disposes individuals to increased risk of thrombosis, though the current evidence body for this is limited to case repots and epidemiological studies [63].

Psychiatric measures as scored in the Hostility and Direction of Hostility Questionnaire (HDHQ) and Symptoms Check List-90 (SCL-90) have been associated with AAS use, with symptom intensity correlating with the severity of misuse [64]. Hypomanic or manic syndromes have also been described as two possible manifestations, with irritable 'roid rage' being the classic lay term that describes aggressive behavior that is seemingly due to AAS use [65]. Pope et al. assessed psychiatric outcome measures between a placebo group and a group that received exogenous testosterone. They concluded that the AAS group had significantly higher scores on the Young Mania Rating Scale (YMRS) $(p=0.002)$, with $16 \%$ of the group being classified as mildly or markedly hypomanic [66]. AAS may also dispose users to impaired cognitive functions or structural brain alterations, with one study that conducted structural MRI brain imaging on AAS users and nonusers noting a negative association between cortical thickness and brain volume and AAS use [67]. Notably, this is in the context of an association between AAS use and poorer performance on cognitive tests [68, 69]. Furthermore, some commentators have raised the possibility of a link between supraphysiologic testosterone levels and dementia through androgenic induction of additional oxidative stress [70].

Infertility following AAS use is secondary to suppression of intratesticular testosterone levels, which can lead to azoospermia or oligozoospermia [71]. It is generally thought that restoration of sperm count and quality after AAS cessation would eventuate with sufficient passage of time, with the 12- to 24-month mark being cited as the timeframe for the bulk of AAS users [72, 73]. One 2020 cross-sectional study of 72 AAS misusers and 31 healthy controls noted no significant difference in sperm output, sperm concentration, and sperm motility between former AAS users and nonusers, with the mean recovery time for these parameters post-AAS cessation being 14 months, 10 months, and 37 months, respectively [74]. Conversely, a 2021 prospective study of AAS users who intended to initiate a cycle discovered that at 1 year follow-up, 34\% of users had a total sperm count below 40 million (normal range $\geq 39$ million) [75]. However, this study followed up participants based on when they were starting AAS use, rather than stopping it, which would provide a more generalizable conclusion. An overarching limitation of the interpretation of all of these studies is that restoration of fertility is defined by the restoration of reproductive physiologic parameters, rather than real-world world outcomes, such as the time to achieve pregnancy. A 2021 Danish study of 545 males who returned an AAS positive result on a blood test discovered that, in the decade prior to the positive result, the AAS group had a significant lower fertility rate compared to the healthy control group, with a rate ratio of 0.74 (95\% CI: $0.60-0.90, p=0.0028)$. In the years after AAS cessation, the AAS group still exhibited a $7 \%$ lower total fertility rate compared to control, though there was no significant group difference for rates of assisted reproduction [76]. Therefore, the current literature tentatively suggests that reproductive recovery may be possible for most former AAS users. However, further research investigating real-world world outcomes, such as the time to achieve pregnancy, is required to deliver more substantiative conclusions.

Hepatotoxicity is a commonly encountered side effect of AAS use, with one study noting AAS related liver injury comprised $8 \%$ of their total cases of drug-induced liver injury [77]. Notably, only $17 \alpha$-alkylated AAS appears to have hepatotoxic properties. While the underlying mechanism behind this is yet to be fully elucidated, increased oxidative stress secondary to increased mitochondrial $\beta$-oxidation has been hypothesized to play a role [78]. The spectrum of AAS induced liver injuries is diverse in possible pathology. Schwingel and colleagues analyzed 182 asymptomatic Brazilian AAS users and reported that $38 \%$ had raised liver markers, $12 \%$ had hepatic steatosis, and there was one case each of hepatocellular adenoma, focal nodular hyperplasia, hepatitis $B$, and hepatitis C [79]. While hepatocellular adenomas are typically benign solitary masses, cases have been described where multiple adenomas had formed in the setting of AAS use and resulted in the patients suffering from hemorrhagic shock that nearly resulted in death $[80,81]$. There are also case reports of hepatocellular carcinoma (HCC) forming in the setting of AAS use, noting that approximately $4 \%$ of hepatocellular adenomas transform to HCC [82]. The mechanisms and association between AAS and hepatic cell proliferation are worthwhile of further exploration.

AAS related renal damage is less studied compared to other adverse effects, although some possible mechanisms include direct toxicity or bile acid nephropathy secondary to AAS related liver injury $[26,83]$. The spectrum of possible AAS related kidney injuries is diverse, ranging from transient fluctuations in creatinine levels to end-stage chronic kidney disease or secondary focal-segmental glomerulosclerosis $d$ [84]. 


\section{Conclusions}

Anabolic-androgenic steroids include a highly varied group of synthetic and endogenous androgens, each with a unique chemical structure and adverse effect profile. Typological depictions of the anabolic-androgenic steroid base have been attempted, with some cross-sectionally derived evidence substantiating the idea that there are distinct user profiles within the user community. However, further work is needed to conceptualize other possible typologies, especially from datasets outside the United Kingdom, and this area is at a very early level of development. Further qualitative stratification may prove beneficial from a public health perspective, especially if policies and interactions at national, regional, and clinician-patient levels are able to be tailored to specific user subtype. General consumption strategies observed in AAS community include administering an exogenous testosterone for distinct periods and then tapering the drug down over a predetermined amount of time. Others combine multiple AAS or augmentative agents as part of a same regimen. Some users never cease exogenous testosterone, instead alternating between high and low doses of AAS. The level of risk stratification or spontaneity regarding consumption strategies is thought to vary between typographic subtypes.

AAS is associated with myriad adverse effects that are pervasive across multiple organ systems. Some AAS users attempt to attenuate side effects such as gynecomastia, androgenic steroid induced hypogonadism, or sexual dysfunction through self-initiating interventions such as tamoxifen, anastrozole, or hCG injections. The adverse effect profile of AAS use has historically been a source of contention, with commentators mixed on the severity of the situation. Our review shows that the adverse effects of AAS are indeed disseminated across multiple organ systems, with the true extent of it yet to be revealed by further, ideally prospectivedesign studies. The increased risk of premature death, development and subsequent hemorrhagic rupture of hepatic adenomas, and the possibility of remaining infertile for up to 2 years after AAS cessation are possible points for the clinician to use to dissuade individuals from misusing AAS.

\section{Conflicts of Interest}

The authors declare that there are no conflicts of interest regarding the publication of this paper.

\section{References}

[1] M. Roman, D. L. Roman, and V. Ostafe, "Computational assessment of pharmacokinetics and biological effects of some anabolic and androgen steroids," Pharmaceutical Research, vol. 35 , no. 2, p. $41,2018$.

[2] J. L. Dotson and R. T. Brown, "The history of the development of anabolic-androgenic steroids," Pediatric Clinics of North America, vol. 54, no. 4, pp. 761-769, 2007.

[3] C. Wu and J. R. Kovac, "Novel uses for the anabolic androgenic steroids nandrolone and oxandrolone in the management of male health," Current Urology Reports, vol. 17, no. 10, p. 72, 2016.
[4] D. Sagoe, H. Molde, and C. S. Andreassen, "The global epidemiology of anabolic-androgenic steroid use: a meta-analysis and meta-regression analysis," Annals of Epidemiology, vol. 24, no. 5, pp. 383-398, 2014.

[5] A. B. Parkinson and N. A. Evans, "Anabolic androgenic steroids: a survey of 500 users," Medicine \& Science in Sports \& Exercise, vol. 38, no. 4, pp. 644-651, 2006.

[6] I. Thiblin, H. Garmo, and M. Garle, "Anabolic steroids and cardiovascular risk: a national population-based cohort study," Drug and Alcohol Dependence, vol. 152, pp. 87-92, 2015.

[7] H. G. Pope, G. Kanayama, and M. Ionescu-Pioggia, "Anabolic steroid users' attitudes towards physicians," Addiction, vol. 99, no. 9, pp. 1189-1194, 2004.

[8] S. Griffiths, S. B. Murray, and D. Mitchison, "Anabolic steroids: lots of muscle in the short-term, potentially devastating health consequences in the long-term," Drug and Alcohol Review, vol. 35, no. 4, pp. 375-376, 2016.

[9] S. Basaria, "Male hypogonadism," Lancet, vol. 383, no. 9924, pp. 1250-1263, 2014.

[10] K. Skorupskaite, J. T. George, and R. A. Anderson, "The kisspeptin-GnRH pathway in human reproductive health and disease," Human Reproduction Update, vol. 20, no. 4, pp. 485-500, 2014.

[11] D. Santi, P. Crépieux, and E. Reiter, "Follicle-stimulating hormone (FSH) action on spermatogenesis: a focus on physiological and therapeutic roles," Journal of Clinical Medicine, vol. 9, no. 4, p. 1014, 2020.

[12] M. Y. Roth, K. Lin, and J. K. Amory, "Serum LH correlates highly with intratesticular steroid levels in normal men," Journal of Andrology, vol. 31, no. 2, pp. 138-145, 2010.

[13] D. J. Handelsman, "Androgen physiology, pharmacology, use and misuse," Edited by K. R. Feingold, B. Anawalt, A. Boyce, G. Chrousos, W. W. de Herder, and K. Dhatariya, Eds., MDText.com, Inc, South Dartmouth, MA,USA, 2000.

[14] C. A. Quigley, A. De Bellis, and K. B. Marschke, "Androgen receptor defects: historical, clinical, and molecular perspectives," Endocrine Reviews, vol. 16, no. 3, pp. 271-321, 1995.

[15] R. S. Swerdloff, R. E. Dudley, and S. T. Page, "Dihydrotestosterone: biochemistry, physiology, and clinical implications of elevated blood levels," Endocrine Reviews, vol. 38, no. 3, pp. 220-254, 2017.

[16] M. Grossmann, "Hypogonadism and male obesity: focus on unresolved questions," Clinical Endocrinology, vol. 89, no. 1, pp. 11-21, 2018.

[17] D. J. Handelsman, "Chapter 138 - androgen physiology, pharmacology, and abuse," in Endocrinology: Adult and Pediatric, J. L. Jameson, L. J. De Groot, D. M. de Kretser, L. C. Giudice, A. B. Grossman, and S. Melmed, Eds., pp. 2368-2393, W.B. Saunders, Philadelphia, PA, USA, Seventh edition, 2016.

[18] E. W. Bergink, P. S. Janssen, and E. W. Turpijn, "Comparison of the receptor binding properties of nandrolone and testosterone under in vitro and in vivo conditions," Journal of Steroid Biochemistry, vol. 22, no. 6, pp. 831-836, 1985.

[19] B. Couzinet, J. Young, and S. Brailly, "The antigonadotropic activity of progestins (19-nortestosterone and 19-norprogesterone derivatives) is not mediated through the androgen receptor," Journal of Clinical Endocrinology \& Metabolism, vol. 81, no. 12, pp. 4218-4223, 1996.

[20] R. Horton, "Dihydrotestosterone is a peripheral paracrine hormone," Journal of Andrology, vol. 13, no. 1, pp. 23-27, 1992. 
[21] A. G. Renehan, "Hormones, growth factors, and tumor growth," Clinical Endocrine Oncology, vol. 2008, pp. 32-40, 2008.

[22] R. W. Casey and J. D. Wilson, "Antiestrogenic action of dihydrotestosterone in mouse breast. Competition with estradiol for binding to the estrogen receptor," Journal of Clinical Investigation, vol. 74, no. 6, pp. 2272-2278, 1984.

[23] B. Zhang, X. J. Hu, and X. Q. Wang, "Human $3 \alpha$-hydroxysteroid dehydrogenase type 3: structural clues of $5 \alpha$-DHT reverse binding and enzyme down-regulation decreasing MCF7 cell growth," Biochemical Journal, vol. 473, no. 8, pp. 1037-1046, 2016.

[24] S. Bhasin, W. E. Taylor, and R. Singh, "The mechanisms of androgen effects on body composition: mesenchymal pluripotent cell as the target of androgen action," Journal of Gerontology: Series A, vol. 58, no. 12, pp. M1103-M10, 2003.

[25] S. Bhasin, L. Woodhouse, and R. Casaburi, "Testosterone dose-response relationships in healthy young men," American Journal of Physiology. Endocrinology and Metabolism, vol. 281, no. 6, pp. E1172-E1181, 2001.

[26] G. D. Albano, F. Amico, and G. Cocimano, "Adverse effects of anabolic-androgenic steroids: a literature review," Health Care, vol. 9, no. 1, p. 97, 2021.

[27] J. M. Eason, S. L. Dodd, and S. K. Powers, "Use of anabolic steroids to attenuate the effects glucocorticoids on the rat diaphragm," Physical Therapy, vol. 83, no. 1, pp. 29-36, 2003.

[28] H. Arazi, H. Mohammadjafari, and A. Asadi, "Use of anabolic androgenic steroids produces greater oxidative stress responses to resistance exercise in strength-trained men," Toxicology Reports, vol. 4, pp. 282-286, 2017.

[29] M. Mayer and F. Rosen, "Interaction of anabolic steroids with glucocorticoid receptor sites in rat muscle cytosol," American Journal of Physiology, vol. 229, no. 5, pp. 1381-1386, 1975.

[30] W. J. Kraemer, N. A. Ratamess, and W. C. Hymer, "Growth hormone (s), testosterone, insulin-like growth factors, and cortisol: roles and integration for cellular development and growth with exercise," Frontiers in Endocrinology, vol. 11, no. 33, 2020.

[31] M. Alén, M. Reinilä, and R. Vihko, "Response of serum hormones to androgen administration in power athletes," Medicine \& Science in Sports \& Exercise, vol. 17, no. 3, pp. 354-359, 1985.

[32] T. Ishikawa, C. Glidewell-Kenney, and J. L. Jameson, "Aromatase-independent testosterone conversion into estrogenic steroids is inhibited by a 5 alpha-reductase inhibitor," The Journal of Steroid Biochemistry and Molecular Biology, vol. 98, no. 2-3, pp. 133-138, 2006.

[33] A. T. Kicman, "Pharmacology of anabolic steroids," British Journal of Pharmacology, vol. 154, no. 3, pp. 502-521, 2008.

[34] R. C. Hickson, K. L. Ball, and M. T. Falduto, "Adverse effects of anabolic steroids," Med Toxicol Adverse Drug Exp, vol. 4, no. 4, pp. 254-271, 1989.

[35] W. Abushareeda, A. Fragkaki, and A. Vonaparti, "Advances in the detection of designer steroids in anti-doping," Bioanalysis, vol. 6 , no. 6, pp. 881-896, 2014.

[36] W. W. Franke and B. Berendonk, "Hormonal doping and androgenization of athletes: a secret program of the German Democratic Republic government," Clinical Chemistry, vol. 43, no. 7, pp. 1262-1279, 1997.

[37] A. S. Bennett, A. Golub, and L. Elliott, "A behavioral typology of opioid overdose risk behaviors among recent veterans in New York City," PLoS One, vol. 12, no. 6, p. e0179054, 2017.

[38] A. Peacock, T. Norman, and R. Bruno, "Typology of alcohol consumers in five Australian nighttime entertainment districts," Drug and Alcohol Review, vol. 35, no. 5, pp. 539-548, 2016.

[39] A. V. Christiansen, A. S. Vinther, and D. Liokaftos, "Outline of a typology of men's use of anabolic androgenic steroids in fitness and strength training environments," Drugs: Education, Prevention \& Policy, vol. 24, no. 3, pp. 295-305, 2017.

[40] R. Zahnow, J. McVeigh, and G. Bates, "Identifying a typology of men who use anabolic androgenic steroids (AAS)," International Journal of Drug Policy, vol. 55, pp. 105-112, 2018.

[41] A. K. Bonnecaze, T. O'Connor, and C. A. Burns, "Harm reduction in male patients actively using anabolic androgenic steroids (AAS) and performance-enhancing drugs (PEDs): a review," Journal of General Internal Medicine, vol. 36, no. 7, pp. 2055-2064, 2021.

[42] F. Hartgens, G. Rietjens, and H. A. Keizer, "Effects of androgenic-anabolic steroids on apolipoproteins and lipoprotein (a)," British Journal of Sports Medicine, vol. 38, no. 3, pp. 253-259, 2004.

[43] G. L. de Souza and J. Hallak, "Anabolic steroids and male infertility: a comprehensive review," BJU International, vol. 108, no. 11, pp. 1860-1865, 2011.

[44] M. R. Graham, B. Davies, and F. M. Grace, "Anabolic steroid use," Sports Medicine, vol. 38, no. 6, pp. 505-525, 2008.

[45] D. Sagoe, J. McVeigh, and A. Bjørnebekk, "Polypharmacy among anabolic-androgenic steroid users: a descriptive metasynthesis," Substance Abuse Treatment, Prevention, and Policy, vol. 10, p. 12, 2015.

[46] S. Karavolos, M. Reynolds, and N. Panagiotopoulou, "Male central hypogonadism secondary to exogenous androgens: a review of the drugs and protocols highlighted by the online community of users for prevention and/or mitigation of adverse effects," Clinical Endocrinology, vol. 82, no. 5, pp. 624-632, 2015.

[47] C. Dandoy and R. S. Gereige, "Performance-enhancing drugs," Pediatric Review, vol. 33, no. 6, pp. 265-272, 2012.

[48] M. Hall and T. H. Trojian, "Creatine supplementation," Current Sports Medicine Reports, vol. 12, no. 4, pp. 240-244, 2013.

[49] C. D. Rahnema, L. I. Lipshultz, and L. E. Crosnoe, "Anabolic steroid-induced hypogonadism: diagnosis and treatment," Fertility and Sterility, vol. 101, no. 5, pp. 1271-1279, 2014.

[50] J. M. Armstrong, R. A. Avant, and C. M. Charchenko, "Impact of anabolic androgenic steroids on sexual function," Translational Andrology and Urology, vol. 7, no. 3, pp. 483-489, 2018.

[51] L. N. Parker, D. R. Gray, and M. K. Lai, "Treatment of gynecomastia with tamoxifen: a double-blind crossover study," Metabolism, vol. 35, no. 8, pp. 705-708, 1986.

[52] L. Casarini, M. Lispi, and S. Longobardi, "LH and hCG action on the same receptor results in quantitatively and qualitatively different intracellular signalling," PLoS One, vol. 7, no. 10, p. e46682, 2012.

[53] A. Ulloa-Aguirre, J. P. Mendez, and V. Diaz-Sánchez, "Selfpriming effect of luteinizing hormone-human chorionic gonadotropin (hCG) upon the biphasic testicular response to exogenous hCG. I. Serum testosterone profile," Journal of Clinical Endocrinology \& Metabolism, vol. 61, no. 5, pp. 926-932, 1985.

[54] M. Depenbusch, S. von Eckardstein, and M. Simoni, "Maintenance of spermatogenesis in hypogonadotropic hypogonadal men with human chorionic gonadotropin alone," European Journal of Endocrinology, vol. 147, no. 5, pp. 617-624, 2002. 
[55] P. J. Turek, R. H. Williams, and J. H. Gilbaugh, "The reversibility of anabolic steroid-induced azoospermia," Journal d'Urologie, vol. 153, no. 5, pp. 1628-1630, 1995.

[56] J. R. Hoffman and N. A. Ratamess, "Medical issues associated with anabolic steroid use: are they exaggerated?" Journal of Sports Science and Medicine, vol. 5, no. 2, pp. 182-193, 2006.

[57] J. van Amsterdam, A. Opperhuizen, and F. Hartgens, "Adverse health effects of anabolic-androgenic steroids," Regulatory Toxicology and Pharmacology, vol. 57, no. 1, pp. 117-123, 2010.

[58] S. Achar, A. Rostamian, and S. M. Narayan, "Cardiac and metabolic effects of anabolic-androgenic steroid abuse on lipids, blood pressure, left ventricular dimensions, and rhythm," The American Journal of Cardiology, vol. 106, no. 6, pp. 893-901, 2010.

[59] H. Horwitz, J. T. Andersen, and K. P. Dalhoff, "Health consequences of androgenic anabolic steroid use," Journal of Internal Medicine, vol. 285, no. 3, pp. 333-340, 2019.

[60] P. Frati, F. P. Busardò, and L. Cipolloni, "Anabolic Androgenic Steroid (AAS) related deaths: autoptic, histopathological and toxicological findings," Current Neuropharmacology, vol. 13, no. 1, pp. 146-159, 2015.

[61] A. L. Baggish, R. B. Weiner, and G. Kanayama, "Cardiovascular toxicity of illicit anabolic-androgenic steroid use," Circulation, vol. 135, no. 21, pp. 1991-2002, 2017.

[62] M. Torrisi, G. Pennisi, and I. Russo, "Sudden cardiac death in anabolic-androgenic steroid users: a literature review," Medicina, vol. 56, no. 11, 2020.

[63] S. Chang, A. B. Münster, and J. Gram, "Anabolic androgenic steroid abuse: the effects on thrombosis risk, coagulation, and fibrinolysis," Seminars in Thrombosis and Hemostasis, vol. 44, no. 8, pp. 734-746, 2018.

[64] T. A. Pagonis, N. V. Angelopoulos, and G. N. Koukoulis, "Psychiatric side effects induced by supraphysiological doses of combinations of anabolic steroids correlate to the severity of abuse," European Psychiatry, vol. 21, no. 8, pp. 551-562, 2006.

[65] R. D. Kersey, D. L. Elliot, and L. Goldberg, "National Athletic Trainers' Association position statement: anabolic-androgenic steroids," Journal of Athletic Training, vol. 47, no. 5, pp. 567-588, 2012.

[66] H. G. Pope, E. M. Kouri, and J. I. Hudson, "Effects of supraphysiologic doses of testosterone on mood and aggression in normal men: a randomized controlled trial," Archives of General Psychiatry, vol. 57, no. 2, pp. 133-140, 2000.

[67] A. Bjørnebekk, K. B. Walhovd, and M. L. Jørstad, "Structural brain imaging of long-term anabolic-androgenic steroid users and nonusing weightlifters," Biological Psychiatry, vol. 82, no. 4, pp. 294-302, 2017.

[68] G. Kanayama, J. Kean, and J. I. Hudson, "Cognitive deficits in long-term anabolic-androgenic steroid users," Drug and Alcohol Dependence, vol. 130, no. 1-3, pp. 208-214, 2013.

[69] M. J. Kaufman, A. C. Janes, and J. I. Hudson, "Brain and cognition abnormalities in long-term anabolic-androgenic steroid users," Drug and Alcohol Dependence, vol. 152, pp. 47-56, 2015.

[70] M. J. Kaufman, G. Kanayama, and J. I. Hudson, "Supraphysiologic-dose anabolic-androgenic steroid use: a risk factor for dementia?" Neuroscience \& Biobehavioral Reviews, vol. 100, pp. 180-207, 2019.

[71] R. El Osta, T. Almont, and C. Diligent, "Anabolic steroids abuse and male infertility," Basic and Clinical Andrology, vol. 26, p. 2, 2016.
[72] L. E. Crosnoe, E. Grober, and D. Ohl, "Exogenous testosterone: a preventable cause of male infertility," Translational Andrology and Urology, vol. 2, no. 2, pp. 106-113, 2013.

[73] P. Y. Liu, R. S. Swerdloff, and P. D. Christenson, "Rate, extent, and modifiers of spermatogenic recovery after hormonal male contraception: an integrated analysis," Lancet, vol. 367, no. 9520, pp. 1412-1420, 2006.

[74] N. Shankara-Narayana, C. Yu, and S. Savkovic, "Rate and extent of recovery from reproductive and cardiac dysfunction due to androgen abuse in men," Journal of Clinical Endocrinology \& Metabolism, vol. 105, no. 6, 2020.

[75] D. L. Smit, M. M. Buijs, and O. de Hon, "Disruption and recovery of testicular function during and after androgen abuse: the HAARLEM study," Human Reproduction, vol. 36, no. 4 , pp. 880-890, 2021.

[76] J. Windfeld-Mathiasen, K. P. Dalhoff, and J. T. Andersen, "Male fertility before and after androgen abuse," Journal of Clinical Endocrinology \& Metabolism, vol. 106, no. 2, pp. 442-449, 2021.

[77] M. Robles-Diaz, A. Gonzalez-Jimenez, and I. Medina-Caliz, "Distinct phenotype of hepatotoxicity associated with illicit use of anabolic androgenic steroids," Alimentary Pharmacology \& Therapeutics, vol. 41, no. 1, pp. 116-125, 2015.

[78] P. Bond, W. Llewellyn, and P. Van Mol, "Anabolic androgenic steroid-induced hepatotoxicity," Medical Hypotheses, vol. 93, pp. 150-153, 2016.

[79] P. A. Schwingel, H. P. Cotrim, and C. R. Santos, "Recreational anabolic-androgenic steroid use associated with liver injuries among Brazilian young men," Substance Use \& Misuse, vol. 50, no. 11, pp. 1490-1498, 2015.

[80] L. Wang, C. Wang, and W. Li, "Multiple hepatocellular adenomas associated with long-term administration of androgenic steroids for aplastic anemia: a case report and literature review," Medicine, vol. 99, no. 28, p. e20829-e, 2020.

[81] D. L. Smit, J. H. Nuijens, and W. de Ronde, "Spontaneous haemorrhage of hepatic adenoma in a patient addicted to anabolic steroids," The Netherlands Journal of Medicine, vol. 77, no. 7, pp. 261-263, 2019.

[82] C. Woodward, J. Smith, and D. Acreman, "Hepatocellular carcinoma in body builders; an emerging rare but serious complication of androgenic anabolic steroid use," Annals of Hepato-Biliary-Pancreatic Surgery, vol. 23, no. 2, pp. 174-177, 2019.

[83] R. L. Luciano, E. Castano, and G. Moeckel, "Bile acid nephropathy in a bodybuilder abusing an anabolic androgenic steroid," American Journal of Kidney Diseases, vol. 64, no. 3, pp. 473-476, 2014.

[84] D. Davani-Davari, I. Karimzadeh, and H. Khalili, "The potential effects of anabolic-androgenic steroids and growth hormone as commonly used sport supplements on the kidney: a systematic review," BMC Nephrology, vol. 20, no. 1, p. 198, 2019. 